\title{
Teacher Questioning in Mathematics Teaching: Feedback that Stimulates Productive Teaching
}

\section{Muhammad Sofwan Mahmud ${ }^{1}$, Roslinda Rosli ${ }^{2}$, Siti Mistima Maat ${ }^{3}$, Nadia Fasha Mohd Drus $^{4}$}

\author{
${ }^{1234}$ Faculty of Education, Universiti Kebangsaan Malaysia \\ roslinda@ukm.my ${ }^{2}$
}

Article History: Received: 11 January 2021; Accepted: 27 February 2021; Published online: 5 April 2021

\begin{abstract}
Providing feedback to the student responses in the oral questioning process is an essential element in helping the students to understand the concept of mathematics. This study was conducted to describe the types of feedback given by primary school mathematics teachers regarding the student response in the oral questioning process when teaching mathematics. This qualitative study employed a multiple case study research design. The data was obtained through observation methods, interviews, document analysis, and field notes. The data collected was analyzed using the constant comparative analysis method to obtain the themes and sub-themes within the primary data. The selection of the study participants used the purposive sampling method, resulting in a total of six primary school mathematics teachers consisting of three new teachers and three experienced teachers. This study found that both the novice and experienced teachers provided a variety of feedback for the students' responses to the oral questioning activities during the mathematics teaching process, such as repeated trial feedback, explanatory feedback and easier questions feedback. This research provides a deeper understanding of how the different types of feedback given by the teachers as part of the oral questioning activities helps the students to stimulate their thinking.
\end{abstract}

Keywords: Teacher Questioning, Mathematics Teaching,Productive Teaching.

\section{Introduction}

Feedback is one of the essential elements found in the oral questioning process, where feedback acts as a response given to the students after the students answer the questions posed to them(Mahmud \& Yunus, 2018). Cotton (2013)used the term 'formative feedback,' defined as information presented to the students to modify their thinking or behavior to enhance their learning. The formation of self-regulation refers to how the students can control aspects of their thinking, motivation, and behavior while learning (Veon, 2016). Cotton (2013) outlined seven principles of good feedback practice when implementing the teaching process:

i. Helps to explain good performance (goals, criteria and expected standards).

ii. Facilitates the development of self-assessment (reflection) in learning.

iii. Communicates high-quality information to the students about their learning.

iv. Encouragesa discussion between the teachers and their peers during the teaching process by always asking for the students' clarification of their responses.

v. Promotes positive motivational beliefs and self-esteem.

vi. Provides an opportunity to close the gap between their current performance and desired performance.

vii. Provides information to the teachers that can be used to help shape their teaching.

Feedback in oral questioning activities is a key element in formative assessments and it is usually defined as the information on how successfully something has been done (Havnes et al., 2012). Andrade and Cizek (2010)stated that the effective use of questioning involves the teachers providing the feedback that is to be absorbed by students passively. Students need to actively process the feedback and interventions to obtain longterm learning effects. Relating the feedback to personal experiences is also a form of relating the environment to the teaching process implemented (Silverman \& Casazza, 2000). Mahmud Yunus ( 2018)stated that effective feedback should be given to the students in accordance with the experience of the students' learning environment to help improve the students' understanding of the mathematical concepts explained to them. This is as well as improving the students' ability to relate the mathematical concepts learned to their daily lives in a more meaningful way.

The most challenging aspect to master is when and how often formative feedback should be given to the students (Black \& Wiliam, 2004). Shute (2008) offers heuristics about when and how often feedback should be given in formative assessments based on the student characteristics (Table 1). Shute (2008) noted that his heuristics are designed for primary school students and acknowledges that older students are more likely to benefit from the delayed feedback provided to complement their increased maturity.

Table1.Best practice feedback (Shute,2008) 


\begin{tabular}{|l|l|l|lr|l|}
\hline & $\begin{array}{l}\text { Time to give } \\
\text { feedback }\end{array}$ & $\begin{array}{l}\text { Type of } \\
\text { feedback }\end{array}$ & $\begin{array}{l}\text { Purpose of } \\
\text { Feedback }\end{array}$ & $\begin{array}{l}\text { Appropriateness } \\
\text { of Details }\end{array}$ \\
\hline $\begin{array}{l}\text { Low achieving } \\
\text { students }\end{array}$ & $\begin{array}{l}\text { Immediate } \\
\text { feedback } \\
\text { important is } \\
\text { correct to } \\
\text { misunderstandings. }\end{array}$ & $\begin{array}{l}\text { Corrective } \\
\text { feedback leading } \\
\text { to problem areas } \\
\text { is more effective. }\end{array}$ & $\begin{array}{l}\text { Assist } \\
\text { students } \\
\text { solving } \\
\text { problem. }\end{array}$ & $\begin{array}{l}\text { Very detailed } \\
\text { feedback to guide } \\
\text { the students to } \\
\text { the next step. }\end{array}$ \\
$\begin{array}{l}\text { High achieving } \\
\text { students }\end{array}$ & $\begin{array}{l}\text { Delayed feedback } \\
\text { to allow the } \\
\text { students to reflect } \\
\text { and correct the } \\
\text { mistakes that they } \\
\text { have made. }\end{array}$ & $\begin{array}{l}\text { Provide in-depth } \\
\text { feedbacktips, } \\
\text { signals and } \\
\text { questions. }\end{array}$ & $\begin{array}{l}\text { Validate the } \\
\text { students' thinking } \\
\text { and challenge } \\
\text { their thinking. }\end{array}$ & $\begin{array}{l}\text { Less detailed } \\
\text { feedback. }\end{array}$ \\
\end{tabular}

Good feedback is where the students are allowed to reflect in addition to providing them with appropriate assistance to help them perform their tasks, to understand the criteria of success, and to actively engage in learning. Not all feedback is formative(Clark, 2011). For example, simply telling the students to 'work hard' is not considered feedback in a formative assessment because such statements do not help them to improve. However, providing the students with specific strategies to implement problem-solving is an example of good feedback practice within the teaching process(Hadley, 2010; Havnes et al., 2012). Criticism should also be avoided as negative feedback can lead to unwanted changes in the attitude of the students (Black \& McCormick, 2010).

\section{Types of Feedback}

There are a variety types of feedback that have been explored by the previous researchers. For example,Dempsey et al. (1993)presented six types of feedback commonly used by teachers in the teaching process, namely:

i. No feedback. This is where the question is asked and then the student responds to the teacher's question. There is no feedback given to the student who cannot determinewhether the student's answer is correct. ii. Simple verification feedback or the knowledge of result (KOR)- The teacher simply informs the student whether the student's answer or response is correct or incorrect.

iii. Correct response feedback or the knowledge of correct response (KCR) -Feedback is given to the students about the correct response to the question.

iv. Try-again feedback or answering until correct (AUC) - Feedback is given to the students when the wrong response is given. It allows the students to make more attempts until they get the correct answer.

v. Delayed Feedback- Late feedback is given to the students to give the students time to forget the wrong responses. This can reduce any proactive distractions. In addition, late feedback also provides space to think in order to correct the mistakes that have been made.

vi. $\quad$ Elaborated feedback - The teacher provides an explanation and justification as to why the students' response is right or wrong.

Kulhavy and Stock (1989)stated that there are three types of explanatory feedback, namely i) specific tasks such as restating the correct answer, ii) grounded instructions, i.e. the explanations taken from the teaching text, and iii) additional explanations such as giving examples or other analogies to improve the level of student understanding. Kulhavy and Stock (1989) also stated that the teachers' feedback should be tailored to thestudents' needs.Chin (2007) stated that there are three types of feedback that are often used by teachers when implementing instructions, as shown in Table 2.

Table 2. Types of feedbacks (Chin, 2007)

\begin{tabular}{|l|l|}
\hline Type of feedbacks & Properties \\
\hline Repetition & $\begin{array}{l}\text { Teachers repeatthe student answers and show agreement explicitly } \\
\text { and implicitly. } \\
\text { Teachers process the student answers and show agreement } \\
\text { Re-processing } \\
\text { Correction }\end{array}$ \\
$\begin{array}{l}\text { Teachers respond to the students' misunderstandings by providing } \\
\text { corrections. }\end{array}$ \\
\hline
\end{tabular}


For repetition feedback, the teacher gives feedback by repeating the students' answers to the teacher's questions and showing their agreement with the answers. In this context, repetitive feedback serves as the minimum encouragement to maintain a more active learning environment. Sipon (2015) explained that minimal encouragement is a response, simple expression or positive movement that encourages the client (student) to continue talking and to explain the problem being discussed. Chin (2007) also emphasizes re-processing the feedback by processing the student answers and showing agreement explicitly and implicitly. Improved student answers through talking can explain how the other students understand how the answer was obtained, especially when it is involving mathematical solution procedures (Tengku Zawawi et al., 2009).Chin (2007) also stated that feedback is used to assist classroom management (Table 3), where it is used to maintain a good learning environment to achieve the learning objectives.

Table 3.Feedback used for classroom management

\begin{tabular}{|l|l|}
\hline Feedback Strategies & Properties \\
\hline Activity management & $\begin{array}{l}\text { Teachers respond to the comments and actions in order to } \\
\text { maintain student involvement in the learning activities. } \\
\text { Relationship }\end{array}$ \\
$\begin{array}{l}\text { Teachers provide feedback to the students to build } \\
\text { relationships outside the field of learning content. }\end{array}$ \\
\hline
\end{tabular}

In addition, Mahmud and Yunus (2018)stated that teachers can also provide contextual feedback and explanatory feedback to help the students understand a mathematical problem from various perspectives, especially related to the diverse and creative problem-solving procedures involved. Mohtar (1996)sees feedback from a more in-depth perspective. He asserts that teacher feedback is given through speech and involves behavior as a signal that can reflect the students' feedback. In this context, he has categorized feedback into linguistic, non-linguistic, non-linguistic verbal, non-linguistic non-verbal, and implicit. The feedback given orally refers to linguistic feedbackwhile the feedback provided upon receiving the students' answers by writing on the whiteboard refers to non-linguistic feedback. Non-linguistic verbal feedback is shown by the teacher by responding to the students' answers with the sound "huh" and so on. The teacher demonstrates non-linguistic and non-verbal feedback by nodding their head. Byun et al. (2015)also explained that feedback like this is nonlinguistic feedback, in that it is feedback given based on non-linguistic signals that are easily understood. Next is implicit feedback, where the teacher continues the lesson by asking other oral questions related to the first oral question. In this case, the teacher accepts the answers given by the students implicitly.

However, there are problems when giving feedback to students when teaching mathematics as a result of the forms of questioning activity implemented (Hadley, 2010). Teachers were found not to provide effective feedback to the students depending on the questioning activities implemented (Shahrill \& Clarke, 2014). In this context, the teacher does not comment or discuss the students' answers. They simply state whether the answer or responsegiven by the student is correct or incorrect. This indirectly makes the learning process less meaningful and does not stimulate the students to think. According to McAninch (2015), this is due to the lack of knowledge and understanding of the teachers in terms of providing feedback on the students' responses in oral questioning activities. Some teachers provide feedback in general, do not focus on repairing specific weaknesses, provide feedback to the whole class, and do not focus on overcoming the student weaknesses individually(McAninch, 2015). This is found to be due to a lack of information and there has been a lack of research done in terms of feedback, especially related to the form of feedback itself(Moss \& Brookhart, 2019).

Studies on providing feedback in the oral questioning process have been done for a long time, but it is still relatively new in the field of mathematics education, especially in primary schools. This study is expected to illustrate a real scenario detailing what kind of feedback is used by primary school mathematics teachers to stimulate their students' thinking in mathematics. This isso then the problems that arise can be identified and solved through their solutions and suggestions.

\footnotetext{
Methodology

The multiple case study approach was used in this qualitative study. Using a purposive sampling technique, six primary school mathematics teachers from six different schools in a district in Negeri Sembilan, Malaysia, were chosen as study participants.Observation, semi-structured interviews, and field notes were used to collect data. The use of different data collection techniques assists the researcher in triangulating the data at the data analysis stage while also reinforcing the obtained findings (Merriam \& Tisdell, 2016).In this study, data were analyzed using constant comparative analysis, which included combining data collection with analysis to recognize trends and themes that emerged from the primary data collected (Merriam \&Tisdell, 2016). The preliminary data analysis started as soon as the fieldwork began.As a result, the processes of data analysis and data collection were carried out concurrently and on an ongoing basis. The Atlas.ti 8 program was used to define themes and sub-themes from the data obtained in this analysis.According Corbin et al. (2014), the validity and reliability of
} 
a study relate to how well the study's results can correctly and reliably reflect the phenomenon under study. As a result, the researcher used the triangulation process, member checking, and peer review in this analysis to improve the study's validity and reliability.

\section{Findings}

Feedback is the teacher's response to the answers within the students' response to the oral questions asked. In this context, the teacher's feedback is seen from the aspect of the answers given by the students such as whether the answer is corrector incorrect, as well as the students' response to the questions that have been asked by the teacher. Various categories arise related to the type of feedback identified by the researcher where each of the types of feedback has a purpose and role in terms of helping the mathematics teaching process go smoother. As a result of the analysis conducted, this study determined there to be three types of feedback used by new teachers and experienced teachers in their mathematics teaching process. The feedback types are as follows:

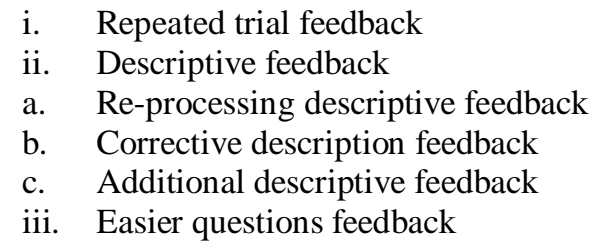

The discussion below describes each category of feedback used by the teachers in the process of oral questioning in mathematics teaching.

\section{Repeated trial feedback}

The study found that apart from simple verification feedback, there are also situations where the teachers provide feedback by allowing the students to continue trying to answer the questions asked when the answers given are initiallyincorrect. Repeated trial feedback is given to the students until the correct answer is obtained. This is shown in the verbatim example below:

Teacher Okay, the length is multiplied by the width of the square. Is there another formula?

Student Length times height.

Teacher Length times height? Wrong.

Student Base times height.

Teacher Okay, almost right. A little more.

Student Length times base.

Teacher Still wrong.

Student $\quad 1 / 2$ times the area of the base times height.

Teacher Yes, excellent, $1 / 2$ times area of the base times height. The answer is right. [Ada, P2/3108-3489]

Teacher Ada provides the students with some attempts to answer the questions that have been asked until they get the right answer. Teacher Ada explained that "I usually delay the time to give the real answer. I will give space for students to try to answer again until they get the correct answer "[Ada, SRI 2 / 21025-21108]. Trial after trial given by the teacher is a form of encouragement used by the teacher to increase the level of student involvement in the teaching process. In this context, each student has the same opportunity to answer the teacher's question because the teacher's question is disseminated to all students openly and not specifically only to specific students [Ana, NL / 09082018].

Teacher Ada also stated that the repeated trial feedback given by the teachers in the form of additional opportunities for the students to answer questions indirectly creates an environment where the students dare to try to answer the questions. It also encourages an environment where the students are not afraid to make mistakes [Ada, SRI 1 / 33666-34036].

Repeated trial feedback is also a form of waiting time given by the teachers to the students. This is because the students are given the opportunity to have a longer time to think in order to get the right answer [Azah, SRI1 / 12565-12612]. Teacher Ada explainedthat every time the students give wrong or inaccurate answers, they are given time, the opportunity to think and the chance to try to answer the question until they get the correct answer [Ada, SRI 1 / 11649-34036].

The students do not have to rush to think and answer the questions because they are provided with enough time to answer better, as stated by Teacher Ana in the following passage: "Students can answer with 'relax'. That 
means, i do not put pressure on students to answer questions. In 'mind setting' he does not want to hurry"[Ana, SRI 1 / 19105-19277].

Teacher Azah also gave his opinion on this matter when she stated that such feedback should be given to students because there are a variety of levels of student mastery. Repeated trial feedback indirectly celebrates and allows weaker students to contribute their responses to the questions asked by the teachers [Azah, NL / 18102018]. This is also important to avoid the dominance of the students who are good at answering the questions posed by the teachers and to prevent other students from feeling marginalized and too lazy to count:

"Students in this class have various abilities. So, we want for this weak student opportunity to try to calculate and give the answer. So, he will not be left behind. If we do not give time, maybe only 'advanced' students will be able to answer. When we do not give this weak student a chance, he will feel marginalized and more lazy to count."

[Azah, SRI2/8242-9302]

The study found that this type of feedback is important to ensure better student engagement and to provide more space for weaker students to be actively involved in the implemented oral questioning activities. In addition, a positive learning environment can be created where students dare to try and are not afraid to give incorrect answers.

\section{Descriptive feedback}

The study findings found that there is also feedback in the form of the teachers' explanation of the student responses. The explanation given by the teacher is a justification and verification as to why the response given by the student is right or wrong. The findings in this section determined there to be three categories of descriptive feedback used by teachers in their teaching of mathematics, namely:

a. Re-processing descriptive feedback

b. Corrective descriptive feedback

c. Additional explanatory feedback

All of the feedback mentioned above is distinct in terms of use and purpose.

\section{Re-processing descriptive feedback}

This type of feedback is a form of explanation given by the teacher to the students after getting the correct response. In this case, the explanation is given by processing the students' answer and showing clear agreement with the students' responses. The following is an example of how re-processing descriptive feedback is applied in mathematics teaching:

Teacher Next, 56.1 centimeters divide by 3. Please give answer in $\mathrm{mm}$.

Student $187 \mathrm{~mm}$.

Teacher That's right. First you divide 56.1 by 3 , and you will get $18.7 \mathrm{~cm}$, then convert to mm by multiply the answer by 10 and you will get $187 \mathrm{~mm}$.

[Roza, P3/5451-5531]

Teacher Why is the measurement the same, Rahman?

Student Because the side size is still the same.

Teacher Yes, because we are still looking for the volume of this shape one by one. Even if it shifts here, you still have to find out how much the volume of cuboid and volume of the cube we just added.

[Nadia, P3/6181-6376]

Teacher Why both of the sides are same?

Student Because the shape is square and it has the same size of length.

Teacher Yes, thas right, the square has four equal sizes of sides. So it has the same size of length and same size of width.

[Ada, P2/12987-13109]

It was found that TeacherRoza, Teacher Nadia, and Teacher Ada provided explanations to the students as a form of feedback by processing the answers given by the students as well as showing an explicit agreement using the words 'correct' and 'yes.' Re-explanatory feedback is given by the teacher when the student gives the correct answer to the question posed by the teacher [Nadia, NL / 24102018]. The teacher's descriptive feedback is based on the students' answers as it aims to help clarify the students' understanding of the content of the lesson discussed. In this context, the student answers are clarified by the teacher by them explaining the procedure of how answers were obtained or by explaining the mathematical concepts related to the problems discussed [Roza, NL / 23082018]. This matter was explained by Teacher Ada: "Sometimes the explanation from the student is not 
clear, so I re-explain what the answer or meaning that the student had conveyed to help the student understand" [Ada, SRI1/19311-19619].

Some students may not be able to hearthe answers given by their peers or they may not understand the answers given by their peers. Therefore, the feedback form of processing information is given by the teacher to overcome all of these problems. Teacher Ada stated this in the following interview excerpts:

"... there may be other students who can not clearly hear the answer given by their friend and so that the other student can understand what exactly the meaning that his friend answered."

[Ada, SRI2/22415-22658]

\section{Corrective Descriptive feedback}

This study also found that teachers can provide explanatory feedback to correct the students' inaccurate or incorrect answers. Corrective description feedback is given by the teacher to correct the students' misconceptions and misunderstandingof the mathematical concepts learned. The following is an example of how corrective description feedback is applied in mathematics teaching:

Teacher How to convert kilometers to meter?

Student Divide 1000.

Teacher Divide?!

Student Divide 100.

Teacher The real answer is multiply 1000. Because one kilometer is equal to 1000 meters, that's why we have to multiply by 1000 .

[Ana, P3/11006-11140]

Student $\quad 3.7 \mathrm{~cm} \times 10=37 \mathrm{~mm}$ " (Students write on the whiteboard in the usual form, but there are errors in the calculation method)

Teacher All right. First of all, when you have to multiply by 10 , this cm unit does not need to be written. You do not have to write this $\mathrm{cm}$ because you want to change it to $\mathrm{mm}$. This 10 is $\mathrm{mm}$.

[Roza, P3/4293-4445]

The above passage shows how the teachers give corrective descriptive feedback to the students during the mathematics teaching process. Teacher Ana corrected the students' misconceptions about the operation required for the conversion of meters to kilometers. The answer given by the student was wrong, so Teacher Ana immediately corrected the mistake made by the student by giving the correct answer, followed by explaining the correct answer. Similarly, TeacherRozaresponded by putting the corrective explanation of the inaccurate calculation procedure on the whiteboard. Not only can the students' answersbe corrected, but when the teacher explains the correction, the students will have the opportunity to understand and correct their thinking of the concepts being studied as explained by Teacher Ada in the interview excerpt below:

"Yes, it aims to correct the answer students gave. Maybe sometimes it is not right because some are right and some are wrong so we will let you know which one is right and which one is wrong. Explain back to the students. So they will better understand what they are learning. "

[Ada, SRI 2/21268-21633]

Teachers also give corrective descriptive feedback to the students to help them understand the reasons why they are wrong. They can use this to learn from the mistakes that they have made. Teacher Ana explained this in the following interview excerpt: "To help students understand why they are wrong and they can learn from their mistakes" [Ana, II/22662-22843].

Corrective descriptive feedback allows the teachers to correct the students' answers through the explanations given. It also provides opportunities for the students to correct their misunderstanding of the concepts learned. This indirectly encourages them to think from various angles in order to understand the cause of the mistakes that they have made.

\section{Additional descriptive feedback}

Based on the observation and verbatim analysis of the teacher teaching, the teachers also provide feedback by providing additional information in answer to the students' responses. The additional descriptive feedback aims to help the students better understand the lesson's content and to see the issue discussed from various points of view. It encourages the proliferation of student thinking. The following is an example of how additional descriptive feedback is applied in mathematics teaching:

Teacher So, if we want to find the shape area, the formulae are length times width. Then, the formulae of the volume are length multiply width multiply height. Is it the same if I say area times high? Same?

Student Same 
Teacher Try you give me one example?

Student Wallpaper.

Teacher Wallpaper, yes right, Isya. We want to buy wallpaper, so how much do we want to buy, so we have to calculate the wall area. Calculate the wall surface area that needs wallpaper, and we just went to the store for the wallpaper.

[Ada, P2/23047-23228]

Based on the above excerpt, Teacher Nadia provided additional descriptive feedback by trying to explain to the students the relationship between the formula of the square area and the formula of volume where the 'length $\mathrm{x}$ width' found in the volume formula also refers to the 'area of the square times height.' Thus the students can see the formula for volume from different thinking angles that can help to develop the students' level of thinking. Teacher Ada also provided additional descriptive feedback to help increase the development of the students' thinking. Teacher Ada asked the students about the materials needed to decorate the classroom by relating it to the concept of the area that they had just learned. Teacher Ada provided additional information on where the students need to measure in reference to the wall area before purchasing the wallpaper needed to decorate the classroom. Therefore, it is clear that feedback in the form of additional information given to the students plays a significant role in helping to boost the students' understanding and thinking on the topic discussed.

According to TeacherAzah, additional descriptive feedback is also given to the students by highlighting alternative solutions to help the students solve mathematical problems [Azah, II/26375-26607]. Examples of the use of additional descriptive feedback by providing alternative solutions to students are shown in the teaching verbatim excerpts below:

Teacher So, what is the answer you will get when you add up this number?

Student The answer is 5.

teacher Yes. Another alternative is you also can cut this number, and you can change it to decimals, and you can also multiply it. So the answer is still 5.

[Roza, P1/9592-9680]

Based on the above description, additional descriptive feedback plays a vital role in the oral questioning process during the mathematics teaching process overall. It is where the additional explanation given is able to encourage the students' understanding of the mathematical concepts learned. Additional explanations in the form of alternative solutions and appropriate examples can help the students make connections about the mathematical concepts learned.

\section{Easierquestions feedback}

The teacher can also provide feedback by giving easier and almost the same questionsto the teacher's original question in the teaching of mathematics. Easier questions are asked of the students when the teacher finds that the students cannot answer the questions asked. This is in order to explain the operating procedures that the students need to understand when answering mathematical questions [Roza, NL / 23082018]. The excerpts below show examples of how easier question feedback is given to the students:

Teacher Now conversion of $\mathrm{mm}$ to $\mathrm{cm}$. All right, the first question, $59 \mathrm{~mm}$ is equals how many $\mathrm{cm}$ ?

Student $\quad$...... (students silent without any answer)

Teacher Okay, let me simplify the question. $20 \mathrm{~mm}$ equals to how many $\mathrm{cm}$ ?

Student $2 \mathrm{~cm}$.

Teacher How you get the answer?

Student Divide by 10.

Teacher Okay good. $20 \mathrm{~cm}$ divide by 10 is equal to $2 \mathrm{~cm}$. So it is still the same as the previous questions.

[Roza, P1/10375-10414]

Teacher Roza initially asked a slightly complex question, specifically how to convert $59 \mathrm{~mm}$ to $\mathrm{cm}$. However, the question did not get a response from the students, causing TeacherRoza to use a simpler question where she tried to reduce the number and use even numbers to help the students understand the concept of converting the unit. TeacherRoza explained that this is intended to help the students understand the mathematical concepts discussed more easily [Roza, SRI 3/19407-19708]. TeacherRaha also expressed the same opinion: "Yes, we usually will simplify the questions such as use small numbers but still in the same situation. This is importantto give them an initial understanding because the use of large number will be a little fibrous." [Raha, II/19956-20138]. 
TeacherAzah also stated the same thing "... maybe we will give an example by using small numbers first so that students can understand what is the first step he has to do first..." [Azah, SRI 2/2816-3129]. In addition, there are situations where the teachers need to change the situation or 'storyline' found in the questions asked to situations that are closer to the student environment in order to help the students understand the questions discussed better. This was explained by Teacher Ada: "Sometimes we need to change the situation in the question to a simpler situation so that students able understand the question" [Ada, SRI 2/32009-32352].

Teacher Ada also added that when the students have successfully answered the simpler question, the teacher can reconnect the understanding that has been acquired by the student with the more difficult original question. In this context, the students' understanding is strengthened by their gradually responding to simpler questions before moving on to the more difficult questions[Ada, NL/20092018]. This is explained in the following interview excerpt: "Yes, first simplify the question and then relate it to the original question, which was a little difficult earlier" [Ada, SRI 1/34917-35403].

A simpler question response as feedback is a form of continuous guidance from the teachers to help the students understand the mathematical concepts. In this context, the teachers try to provide a simpler picture of the problem through smaller numbers, easier operations, or simpler situations to help students make a connection to the more challenging original problem so then the teaching process can be carried out gradually.

Based on the above findings, there were various strategies used by mathematics teachers when providing feedback on the student responses in the oral questioning activities conducted throughout the observed mathematics teaching process. This strategy can help the teachers undertake assessments and further actions in their teaching. Overall, it was found that each type of feedback used by teachers in response to the students 'answers has its own role. It is very important for mathematics teachers to use appropriate feedback so then the students' understanding and learning of the mathematical topics can be improved,stimulating productive thinking.

\section{Discussion}

The study found that new and experienced teachers alike provided various forms of feedback to the students' responses in the oral questioning process implemented. In the context of oral questioning, giving feedback to the students' responses is a must in order to build continuous two-way communication. It has a positive value when applied by the teachers as the teachers still respond to the various student responses regardless of whether the response given is wrong or right. Therefore, through the students' responses, various forms of feedback have been created to meet the needs of the mathematics teaching implemented.

The teachers were found to provide repeated trial feedback for inaccurate or incorrect student responses. In this context, the students can either try a few times or open up the opportunity to other students to try to answer the oral questions until they get the correct answer. This finding coincides with the chain of oral questioning found in the IRF Model where there is the pattern of I-R1-R2-R3-F occurs during teacher questioning. This is where the teacher allows them to try to respond repeatedly, and where various students are involved in the process before providing feedback to thestudents (Molinari et al., 2013). Repeated trial feedback is an important form of feedback that should be implemented in the oral questioning process as it is where the students have an equal opportunity to try to answer the question until they get the correct answer. A positive competitive value can be created where the students race to try to answer the questions. It also encourages the active involvement of all students in the mathematics teaching process that has been implemented.

Repeated trial feedback is also seen of as a way for teachers to give the students more time to think of answers, referred to as the waiting time. A longer time allotted to the students to find the answers allows the students to give more accurate responses, reducing the probability of the students making mistakes while encouraging more students to voluntarily try to respond until they get the correct answer. This is especially important to help weaker students be more involved in the oral questioning process. This is because most students feel that the subject of mathematics is difficult (Kaya et al., 2014)

The study findings also show that teachers provide descriptive feedback in the form of re-processing, corrective explanations, and additional descriptive feedback. It was found that the teachers provide explanations for the students as a form of feedback by processing the answers given by the students as well as showing explicit agreement using the words 'correct' and 'yes.' In this context, the teacher uses the answers given by the students in the explanation given to the students in return. The answers given by the students are improved through the description of the processing by the teacher, allowing the students to get a clearer explanation of the response given by their peers. Tengku Zawawi et al. (2009)explained that the skill of the processing answers given by the students is one of the important elements of pedagogical content knowledge involved in the process of teaching mathematics.The student's answers will be clarified and expandedon to help improve the students' understanding. This can help to reduce the students' misunderstandingof the mathematical problem-solving concepts and algorithms that are discussed, especially for weaker students. 
It was also found that teachers also provide corrective descriptive feedback to correct the students' misconceptions of the mathematical concepts discussed. In this context, the teacher states that the response given is wrong. Theteacher explains why the answer given is wrong, more importantly. Providing corrective feedback in the form of an explanation is an important thing to help the students correct their understanding while providing an opportunity for the students to reflect on the mistakes made while helping them improve their learning and organize their mathematical problem-solving strategies better (Mahmud, 2019).

However, it was found that there is a situation where the teacher immediately corrects the student after the student gives an inaccurate response. This is found to contradict with the opinion of Kaya et al. (2014)in that students should be given more time to rethink their answers when the answers given are incorrect before providing a corrective explanation. However, the researchers thought that corrective descriptive feedback should be given according to the students' circumstances and level of ability. This indirectly supports Gagne's teaching theory, which emphasizes that planned or implemented teaching should consider the level of student ability so then the teaching process implemented can meet the various learning needs of the students(Driscoll, 2000; Gagne, 1970). In this context, the researcher agrees with Shute (2008)who stated that 'immediate feedback' should be given to weaker students and 'delayed feedback' should be given to smarter students. Therefore, it is important to help the students relate the mistakes made with the feedback of the teacher's correction in order to modify their understanding of the correct mathematical understanding.

Furthermore, the study findings also show that the teachers provide additional descriptive feedback in response to the answers given by the students in the oral questioning process conducted. The additional explanations given by the teachers use a variety of additional examples and analogies that are simpler. This indirectly helps the teachers implement elements across the curriculum in the process of teaching mathematics. This can indirectly help the students understand a mathematical problem from various perspectives and alternatives, especially when it is related to diverse and creative problem-solving procedures(Yoong, 2012). However, it should be ensured that the teachers havea solid knowledge foundation, especially knowledge related to the mathematical content, when providing information and when implementing various other examples in the process of teaching mathematics (Rahman et al., 2018).

Besides, easier question feedback is also given to the students in the form of simpler questions when it is found that the students cannot answer the original questions posed to them. Simpler questions are questions in the same context that are posed to students to help them understand the content and procedures of the mathematical solutions required. In this context, the students' thinking will be directed in order to plan real solutions to the mathematical problems posed to the students. It has been found relevant to be implement in low-achieving classrooms to ensure ongoing involvement and interaction from thestudents. Not only that butimplementing this form of feedback also allows the teachers to ask questions according to the level of ability of the students as recommended by the (Mahmud et al. 2020). Easier question feedback is also referred to as the advanced tolerance teaching approach. It can help the students understand the mathematical concepts as they are discussed differently, as stated in Gagne's Theory of Instruction (1970).

However, when providing feedback to the students, the teachers need to provide an appropriate explanationof the effects and consequences of such negative actions and avoid giving feedback in the form of criticism or insults. This is important to prevent emotional disorders among the students. It can cause the unwanted behavior to be repeated by the students as a sign of protest. It has been emphasized by Black and McCormick (2010) that criticism should be avoided as negative feedback that can lead to unwanted changes in the attitude of the students.

\section{Conclusion}

In conclusion, teachers use various types of feedback in response to the answers given by the students in the process of oral questioning. All types of feedback discussed have their role, serving as various forms of response to the students and being a catalyst for the implemented mathematics teaching process. However, it must be ensured that negative feedback such as criticism and excessive student scolding should be avoided, especially among new teachers, in order to create a more conducive teaching and learning environment.

\section{References}

1. Andrade, H., \& Cizek, G. J. (2010). Handbook of Formative Assessment. In Routledge. New York: Routledge.

2. Black, P., \& McCormick, R. (2010). Reflections and new directions. Assessment \& Evaluation in Higher Education, 35(5), 493-499. https://doi.org/10.1080/02602938.2010.493696

3. Black, P., \& Wiliam, D. (2004). The formative purpose: Assessment must first promote learning. Yearbook of the National Society for the Study of Education, 103(2), 20-50.

4. Byun, B., Chou, P. A., Czerwinski, M. P., Kapoor, A., \& Lee, B. (2015). Non-Linguistic Signal Detection 
and Feedback. Washington DC.

5. Chin, C. (2007). Teacher questioning in science classrooms: Approaches that stimulate productive thinking. Journal of Research in Science Teaching, 44(6), 815-843.

6. Clark, I. (2011). Formative Assessment: Policy, Perspectives and Practice. Florida Journal of Educational Administration \& Policy, 4(2), 158-180.

7. Corbin, J., Strauss, A., \& Strauss, A. L. (2014). Basics of qualitative research. California: SAGE Publications, Incorporated.

8. Cotton, D. M. (2013). Elementary Teacher Use of Formative Assessment. Unpublished doctoral dissertationn, Gardner-Webb University.

9. Dempsey, J. V, Discoll, M. P., \& Swindell, L. K. (1993). Text-Based Feedback. In E. T. Publications (Ed.), Interactive Instruction and Feedback (p. 384). New Jersey: Educational Technology Publications.

10. Driscoll, M. P. (2000). Gagne's Theory of Instruction. In Psychology of Learning for Instruction (pp. 341-373). Boston: Allyn \& Bacon.

11. Gagne, R. M. (1970). The Conditions of Learning. New York: Holt, Rinehart \& Winston.

12. Hadley, G. (2010). An Analysis of Questioning and Feedback Strategies Using the IRF Framework. United Kingdom.

13. Havnes, A., Smith, K., Dysthe, O., \& Ludvigsen, K. (2012). Studies in Educational Evaluation Formative assessment and feedback: Making learning visible. Studies in Educational Evaluation, 38(1), 21-27. https://doi.org/10.1016/j.stueduc.2012.04.001

14. Kaya, S., Kablan, Z., \& Rice, D. (2014). Examining question type and the timing of IRE pattern in elementary science classrooms. International Journal of Human Sciences, 11(1), 621-640. https://doi.org/10.14687/ijhs.v11i1.2730

15. Kulhavy, R. W., \& Stock, W. A. (1989). Feedback in written instruction: The place of response certitude. Educational Psychology Review, 1(4), 279-308.

16. Mahmud, M. S. (2019). The Role of Wait Time in the Process of Oral Questioning in the Teaching and Learning Process of Mathematics. International Journal of Advanced Science and Technology Vol., 28(16), 691-697.

17. Mahmud, M. S., \& Yunus, A. S. M. (2018). The Practice Of Giving Feedback Of Primary School Mathematics Teachers In Oral Questioning Activities. Journal of Advanced Research in Dynamical and Control Systems, 10(12), 1336-1343.

18. Mahmud, M. S., Yunus, A. S. M., Ayub, A. F. M., \& Sulaiman, T. (2020). Enhancing Mathematical Language Through Oral Questioning in Primary School. International Journal of Learning, Teaching and Educational Research, 19(5), 395-410.

19. McAninch, M. J. (2015). A Qualitative Study Of Secondary Mathematics Teachers ' Questioning, Responses, And Perceived Influences. Unpublished doctoral dissertation, University of Iowa.

20. Merriam, S. B., \& Tisdell, E. J. (2016). Qualitative Research A Guide to Design and Implementation. San Francisco: Jossey-Bass Inc Pub.

21. Mohtar, T. M. T. (1996). Effects of teacher feedback on student behaviour during English Language lessons. Tesis Doktor Falsafah yang tidak diterbitkan, Universiti Malaya.

22. Molinari, L., Mameli, C., \& Gnisci, A. (2013). A Sequential Analysis of Classroom Discourse in Italian Primary Schools: The Many Faces of the IRF Pattern. British Journal of Educational Psychology, 83(3), 414-430. https://doi.org/10.1111/j.2044-8279.2012.02071.x

23. Moss, C. M., \& Brookhart, S. M. (2019). Advancing formative assessment in every classroom: A guide for instructional leaders. ASCD.

24. Rahman, M. N. A., Zamri, S. N. A. S., \& Eu, L. K. (2018). Kajian Meta-Analisis Pengetahuan Guru Matematik Di Malaysia [Meta-Analysis Study of Mathematics Teachers' Knowledge in Malaysia]. Jurnal Kurikulum \& Pengajaran Asia Pasifik, 6(2), 11-22.

25. Shahrill, M., \& Clarke, D. J. (2014). Brunei Teachers' Perspectives on Questioning: Investigating the Opportunities to "Talk" in Mathematics Lessons. International Education Studies, 7(7). https://doi.org/10.5539/ies.v7n7p1

26. Shute, V. J. (2008). Focus on formative feedback. Review of Educational Research, 78(1), 153-189.

27. Silverman, S. L., \& Casazza, M. E. (2000). Learning \& Development: Making Connections To Enhance Teaching. Higher and Adult Education Series. San Francisco, CA: Jossey-Bass Inc Pub.

28. Sipon, S. (2015). Kaunseling Kelompok [Group Counseling]. Nilai, Negeri Sembilan: Penerbit Universiti Sains Islam Malaysia.

29. Tengku Zawawi, T. Z., Ramlee, M., \& Abdul Razak, H. (2009). Pengetahuan Pedagogi Isi Kandungan Guru Matematik bagi Tajuk Pecahan : Kajian Kes di Sekolah Rendah [Pedagogical Content Knowledge of Mathematics Teachers for Fractional Titles: A Case Study in Primary Schools]. Jurnal Pendidikan Malaysia [Malaysian Journal of Education], 34(1), 131-153.

30. Veon, K. E. (2016). A Case Study of Teachers' Practices using Formative Assessment for Fifth Grade 
Mathematics Students. Unpublished doctoral dissertation, Northcentral University.

31. Yoong, W. K. (2012). Use of student mathematics questioning to promote active learning and metacognition. 12th International Congress on Mathematical Education (ICME-12), 8-15. 